\title{
Use of Chronic Medications Among Patients with Non-Valvular Atrial Fibrillation
}

\author{
Paul T. Kocis ${ }^{1} \cdot{\text { Guodong } \text { Liu }^{2} \cdot \text { Dinara Makenbaeva }}^{3} \cdot$ Jeffrey Trocio $^{4}$. \\ Diana Velott ${ }^{2} \cdot$ JoAnn B. Trainer $^{4}$ - Younos Abdulsattar ${ }^{4}$ Marta I. Molina ${ }^{3}$. \\ Douglas L. Leslie ${ }^{2}$
}

Published online: 10 May 2016

(c) The Author(s) 2016. This article is published with open access at Springerlink.com

\begin{abstract}
Background Frequency of administration (once daily versus more than once daily) is believed to be an important consideration affecting drug choice.

Objective The aim of this study was to describe the characteristics of patients with non-valvular atrial fibrillation (NVAF) and the extent to which they take chronic medications, other than anticoagulants, more frequently than once daily.

Methods Using data from a large, national database of health insurance claims, patients with a diagnosis of
\end{abstract}

Paul T. Kocis

pkocis@hmc.psu.edu

1 Anticoagulation Clinic, Penn State Health, Milton S. Hershey Medical Center, Hershey, PA, USA

2 Public Health Sciences, Penn State University, College of Medicine, Hershey, PA, USA

3 Bristol-Myers Squibb, Plainsboro, NJ, USA

4 Pfizer, New York, NY, USA
NVAF between 1 July 2008 and 30 September 2011 were identified, along with their prescription medications, to determine the proportion of patients taking chronic medications more than once a day. Prescription medications, co-morbidities, and $\mathrm{CHADS}_{2}$ and $\mathrm{CHA}_{2} \mathrm{DS}_{2}-$ VASc scores were evaluated. $\mathrm{CHADS}_{2}$ assesses the risk of stroke in NVAF patients with the following risk factors: Congestive heart failure, Hypertension, Age $\geq 75$ years, Diabetes mellitus, and history of prior Stroke or transient ischemic attack. The $\mathrm{CHA}_{2} \mathrm{DS}_{2}$-VASc score adds the following risk factors to the $\mathrm{CHADS}_{2}$ score: Age 65-74 years, Vascular Disease, and Sex Category (Female).

Results Overall, 324,172 patients with NVAF with mean $\mathrm{CHADS}_{2}$ and $\mathrm{CHA}_{2} \mathrm{DS}_{2}$-VASc scores of 1.51 and 3.08, respectively, were included in the study. Of these patients, $299,716(92.5 \%)$ took chronic medications, with an average of 6.9 medications per patient, and 215,527 (66.5\% of all patients or $71.9 \%$ of those taking chronic medications) took medications more than once per day.

Conclusion Use of chronic medications other than anticoagulants is common among patients with NVAF, and medications are typically taken multiple times per day. The average number of medications per patient and multiple therapeutic classes prescribed underscore the clinical complexity of NVAF patients. Hence, the choice of a once daily anticoagulant versus a more than once daily anticoagulant may be less relevant in a real world NVAF population in terms of a potential convenience benefit. 


\section{Key Points}

This study examines the extent to which patients with non-valvular atrial fibrillation (NVAF) take a variety of different chronic medications other than oral anticoagulants more than once a day.

Of the 324,172 patients with NVAF included in the study, $92.5 \%$ were prescribed chronic medications other than oral anticoagulants, and $66.5 \%$ were identified as taking these medications more than once per day. Among patients who were prescribed chronic medications, $71.9 \%$ were identified as taking their medications more than once per day.

Among the NVAF patients who took chronic medications, the mean number of medications taken was 6.9 and the median was 6 . The mean number of therapeutic classes was 6.4 and the median was 6 .

The average number of medications per patient and multiple therapeutic classes prescribed underscore the clinical complexity of NVAF patients.

Almost half (46.8\%) of our sample of NVAF patients with $\mathrm{CHADS}_{2} \geq 1$ received no oral anticoagulant treatment.

\section{Introduction}

\subsection{Atrial Fibrillation}

Atrial fibrillation (AF) is the most common cardiac arrhythmia and strongest independent risk factor for stroke $[1,2]$. Non-valvular atrial fibrillation (NVAF), which comprises the majority of AF [3], is defined as a rhythm disturbance occurring in the absence of rheumatic mitral valve disease, a prosthetic heart valve, or mitral valve repair [1]. $\mathrm{CHADS}_{2}$ is a commonly used risk stratification scheme for assessing the risk of stroke in NVAF patients with the following risk factors: Congestive heart failure, Hypertension, Age $\geq 75$ years, Diabetes mellitus, and history of prior Stroke or transient ischemic attack [4, 5]. However, the 2014 AHA/ACC/HRS Guideline for the Management of Patients with Atrial Fibrillation recommends replacing the $\mathrm{CHADS}_{2}$ score with the more comprehensive $\mathrm{CHA}_{2} \mathrm{DS}_{2}$-VASc score in order to define stroke risk in those individuals at low risk [6]. The $\mathrm{CHA}_{2} \mathrm{DS}_{2^{-}}$ VASc score adds the following risk factors to the $\mathrm{CHADS}_{2}$ score: Age 65-74 years, Vascular Disease, and Sex Category (Female). Two points are assigned to the following risk factors: Age $\geq 75$ years and a history of prior Stroke or transient ischemic attack [6].

\subsection{Oral Anticoagulants}

Although warfarin, a vitamin $\mathrm{K}$ antagonist, has been the standard of care for stroke prevention in AF patients since it was introduced approximately 60 years ago [7], there are several limitations associated with its use, such as potential drug interactions, the need to maintain a consistent vitamin $\mathrm{K}$ diet, the need for frequent INR monitoring, and the clinical importance of keeping the dose within the therapeutic range [8]. However, several new oral anticoagulants have recently been approved for use. Dabigatran, rivaroxaban, and apixaban have been approved by the US Food and Drug Administration (FDA) to reduce the risk of stroke in NVAF patients. Advantages of these drugs are that they have a quick onset/ offset of action [9], and do not have the vitamin $\mathrm{K}$ food interactions or the required International Normalized Ratio (INR) monitoring associated with warfarin. Apixaban and dabigatran $150 \mathrm{mg}$ significantly reduced stroke or systemic embolism when compared to warfarin in the ARISTOTLE [10] and RE-LY [11] clinical trials, respectively, while rivaroxaban demonstrated non-inferiority when compared to warfarin in the ROCKET-AF [12] clinical trial. In addition, the risk of major bleeding was significantly reduced with apixaban, while dabigatran $150 \mathrm{mg}$ and rivaroxaban did not result in significantly lower rates of major bleeding when compared to warfarin. Among the currently available oral anticoagulant medications to reduce the risk of stroke in NVAF patients, rivaroxaban and warfarin are recommended to be taken once a day and dabigatran and apixaban are recommended to be taken twice a day.

Patients with NVAF may have other co-morbid conditions that require them to take chronic medications. Also, little is known about what chronic medications patients with NVAF take, and the likelihood that NVAF patients take chronic medications other than oral anticoagulants more than once per day, in the context of an NVAF population profile in a real world setting.

\subsection{Study Objective}

The objective of this study was to describe the demographic and clinical characteristics of patients with NVAF with at least one risk factor for stroke, and estimate the proportion of these patients that take chronic medications more than once per day.

\section{Methods}

\subsection{Data Source}

De-identified data for this study were obtained from the MarketScan $^{\circledR}$ Commercial Claims and Encounters 
(MarketScan) database, constructed and maintained by Truven Health. The MarketScan database consists of reimbursed health care claims for employees, retirees, and their dependents of over 250 medium and large employers and health plans throughout the USA. These employers self-insure their enrollees through employer sponsored health plans. The MarketScan database includes claims information from more than 130 payers, and describes the healthcare service use and expenditures for approximately 97 million individuals per year. The database is divided into subsections, including inpatient claims, outpatient claims, outpatient prescription drug claims, and enrollment information. Claims data in each of the subsections contain a unique patient identifier (de-identified) and include information on patient age, gender, geographic location, and type of health plan. The study used de-identified data from 1 January 2008 through 30 September 2012.

\subsection{Study Sample}

Patients 18 years of age and older with at least two outpatient claims with a diagnosis of AF at least 30 days apart were identified using the International Classification of Disease, 9th Edition (ICD-9) code 427.31. Patients with any evidence of rheumatic mitral stenosis or a prosthetic heart valve (ICD-9 codes 394.4, 394.2, 396.0, 396.1, 396.8, 746.5, V42.2, or V43.3; or Current Procedural Terminology codes 33405, 33420, 33422, 33425, 33426, 33427, 33430 , or 33496) were excluded. Finally, only patients with a $\mathrm{CHADS}_{2}$ score of at least 1 were included in the study sample.

Patients were identified in the MarketScan database as illustrated in Fig. 1. The identification period started on 1 July 2008 to ensure a 6 month baseline period and ended on 30 September 2011 to ensure at least 12 months of follow-up. The date of the first qualifying NVAF visit was defined as the study index date. The presence of co-morbid conditions was assessed during the 6 month baseline period, and use of chronic medications was tracked during the 12 month follow-up period. Patients were required to be continuously enrolled during the 18 month study period (Fig. 1).

\subsection{Study Design}

For each medication prescribed to each patient (excluding oral anticoagulants), the total number of days supplied was determined by summing the days supply for each prescription for the medication during the follow-up period. Chronic medications were defined as those with at least 90 total days supply. The majority of non-oral prescription medications (e.g., topicals, creams, ointments, patches) were not included in this list of chronic medications. Oral medications that were also not included were analgesics, anti-infectives, laxatives, and other medications that could be used acutely or on an as needed basis, or for which the frequency of the maintenance medication may be different when prescribed for an acute indication. We also did not include over-the-counter drugs, such as aspirin, since use of these drugs cannot be reliably captured in claims data.

For each chronic medication identified, the FDA approved prescribing information was examined to determine the recommended frequency of administration. Chronic medications were classified as once daily versus more than once daily according to the prescribing information. In addition, chronic medications were also classified as being taken in the morning if the prescribing information indicated that the medication should be taken in the morning or on an empty stomach, or classified as being taken in the evening if the prescribing information indicated that the medication should be taken in the evening, with the largest meal, or at bedtime. In cases where the prescribing information did not explicitly indicate when the medication should be taken, or if the frequency of administration depended on clinical factors or symptoms, the number of prescribed "dosage units" (e.g., tablets or capsules) per day was computed by dividing the number of dosage units prescribed by the days supply. For these medications, the total number of milligrams of medication taken each day
Fig. 1 Identification period for the non-valvular atrial fibrillation (NVAF) study population

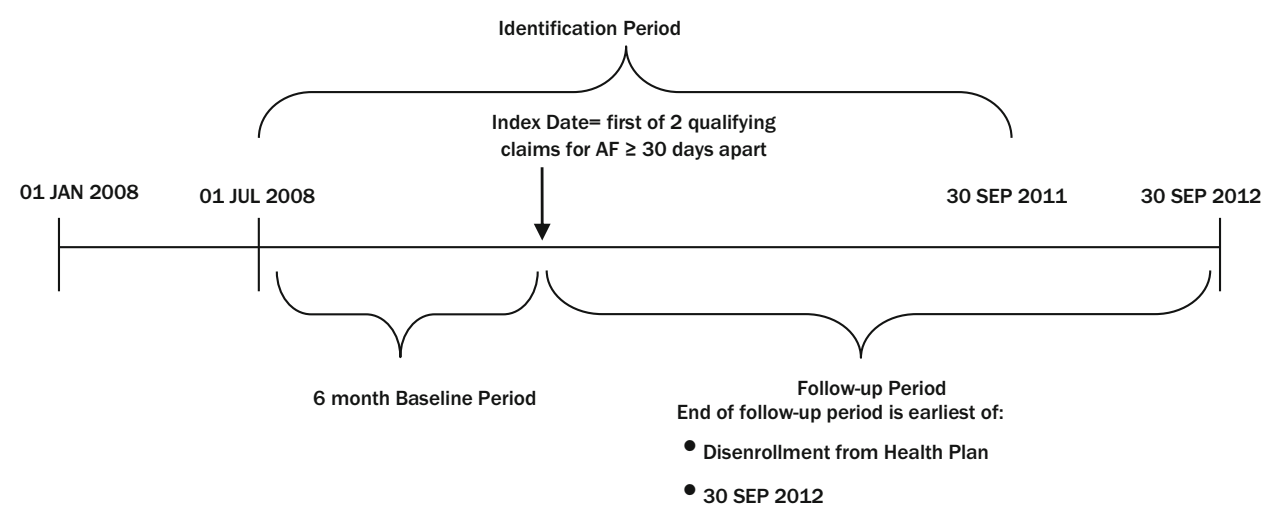


was also determined by multiplying the medication strength by the number of dosage units per day.

\subsection{Medication Portfolio}

A "medication portfolio" was developed for each NVAF patient to characterize the frequency with which the patient took chronic medications, other than oral anticoagulants, on a daily basis. Patients were identified as taking chronic medications more than once per day if any of the following were true: (i) the medication portfolio included a drug that should be taken more than once per day per the drug's prescribing information; (ii) the medication portfolio included a drug that should be taken in the morning and another drug that should be taken in the evening; or (iii) the medication portfolio included a drug for which the frequency of administration was unclear, the number of dosage units per day was greater than 1, and the total milligrams per day was equal to an available dose of the medication. In this last scenario, if the patient was prescribed multiple dosage units per day for a daily dose of medication that could have been supplied in a single dosage unit, then we assume that patient was taking the medication more than once per day. Consider the following example. Suppose a patient was prescribed a 30 day supply of 60 bupropion SR $100 \mathrm{mg}$ tablets, which can be dosed differently depending on whether the patient has hepatic impairment. For this hypothetical prescription, there are two tablets to be taken each day for a total daily dose of $200 \mathrm{mg}$. Since there is a $200 \mathrm{mg}$ tablet strength also available for this medication, we assume that the patient was instructed to take each of the $100 \mathrm{mg}$ tablets at different times of the day, since they would likely have been prescribed the $200 \mathrm{mg}$ tablet if the physician intended that the patient take the entire $200 \mathrm{mg}$ daily dose at once.

\subsection{Analysis}

Demographic and clinical measures were constructed to describe the characteristics of the study sample such as age, gender, geographic region, and $\mathrm{CHADS}_{2}$ and $\mathrm{CHA}_{2} \mathrm{DS}_{2}$ VASc risk categories. The proportion of NVAF patients with $\mathrm{CHADS}_{2} \geq 1$ that took chronic medications, other than anticoagulants, more than once per day was then determined. Patients who took medications more than once per day were stratified by either not taking an anticoagulant or by taking warfarin, dabigatran, or rivaroxaban. Apixaban was not included as an option because it was not approved for use until December 2012 and our data were collected only through September 2012; aspirin was not included because it is available over the counter and is not reliably captured in claims data. When a patient has been prescribed more than one anticoagulant during the follow-up period, they were assigned to the group according to the anticoagulant that was prescribed for the longest duration of the 90 day follow-up period. As a sensitivity analysis, we also classified patients according to their oral anticoagulation therapy on the last day of the follow-up period. Consistent with the published literature (e.g., Amin et al. [16]), patients having more than a 60 day gap in refilling warfarin were categorized as being "off warfarin."

\section{Results}

Overall, 324,172 NVAF patients were selected for the study. Characteristics of the sample are presented in Table 1. The average age of the study sample was 75.3 and the mean $\mathrm{CHADS}_{2}$ and $\mathrm{CHA}_{2} \mathrm{DS}_{2}$-VASc scores were

Table 1 Characteristics of the non-valvular atrial fibrillation (NVAF) sample $(N=324,172)$

\begin{tabular}{|c|c|c|}
\hline Characteristic & $N$ & $\%$ \\
\hline \multicolumn{3}{|l|}{ Age (years) } \\
\hline Mean \pm SD & $75.3 \pm 11.8$ & \\
\hline Median & 78 & \\
\hline \multicolumn{3}{|l|}{$\mathrm{CHADS}_{2}$} \\
\hline Mean \pm SD & $1.51 \pm 0.66$ & \\
\hline Median & 1 & \\
\hline \multicolumn{3}{|l|}{$\mathrm{CHA}_{2} \mathrm{DS}_{2}-\mathrm{VASc}$} \\
\hline Mean \pm SD & $3.08 \pm 1.23$ & \\
\hline Median & 3 & \\
\hline Male gender & 177,126 & 54.6 \\
\hline \multicolumn{3}{|l|}{ Geographic region (USA) } \\
\hline North East & 53,980 & 16.7 \\
\hline North Central & 108,349 & 33.4 \\
\hline South & 106,798 & 32.9 \\
\hline West & 54,454 & 16.8 \\
\hline Unknown & 591 & 0.2 \\
\hline \multicolumn{3}{|c|}{$\mathrm{CHADS}_{2} / \mathrm{CHA}_{2} \mathrm{DS}_{2}$-VASc risk factors } \\
\hline Congestive heart failure & 56,026 & 17.3 \\
\hline Hypertension & 169,550 & 52.3 \\
\hline Age $\geq 75$ years & 196,735 & 60.7 \\
\hline Diabetes & 47,631 & 14.7 \\
\hline Prior stroke/TIA & 8969 & 2.8 \\
\hline Vascular disease & 94,115 & 29.0 \\
\hline Age $65-74$ years & 49,578 & 15.3 \\
\hline Sex category (female) & 147,046 & 45.4 \\
\hline
\end{tabular}

$S D$ standard deviation, $\mathrm{CHADS}_{2}$ Congestive Heart Failure, Hypertension, Age $\geq 75$ years, Diabetes Mellitus, and Prior Stroke or Transient Ischemic Attack, $\mathrm{CHA}_{2} \mathrm{DS}_{2}-\mathrm{VASc}$ Congestive Heart Failure, Hypertension, Age $\geq 75$ years, Diabetes Mellitus, Prior Stroke or Transient Ischemic Attack, Vascular Disease, Age 65-74 years, and Sex Category (Female Gender). Derived from NVAF patients with $\mathrm{CHADS}_{2} \geq 1$ 
Table 2 Non-valvular atrial fibrillation (NVAF) patients prescribed chronic medications more than once per day in the last 90 days

\begin{tabular}{|c|c|c|c|c|c|c|c|}
\hline $\begin{array}{l}\text { Medication } \\
\text { Group }\end{array}$ & $\begin{array}{l}\text { Number of } \\
\text { Patients }\end{array}$ & $\begin{array}{l}\% \text { of } \\
\text { Patients }\end{array}$ & $\begin{array}{l}\text { Patients Prescribed } \\
\text { Chronic Medications }\end{array}$ & $\begin{array}{l}\% \text { Patients } \\
\text { Prescribed Chronic } \\
\text { Medications }\end{array}$ & $\begin{array}{l}\text { Patients Prescribed } \\
\text { Chronic Medications }>1 \\
\text { per Day }\end{array}$ & $\begin{array}{l}\% \text { of All } \\
\text { Patients }\end{array}$ & $\begin{array}{l}\% \text { of Chronic } \\
\text { Medication } \\
\text { Patients }\end{array}$ \\
\hline All patients & 324,172 & & 299,716 & 92.5 & 215,527 & 66.5 & 71.9 \\
\hline No anticoagulant & 151,761 & 46.8 & 130,302 & 85.9 & 91,580 & 60.3 & 70.3 \\
\hline Any anticoagulant & 172,411 & 53.2 & 169,414 & 98.3 & 123,947 & 71.9 & 73.2 \\
\hline Warfarin & 162,871 & 50.2 & 159,997 & 98.2 & 116,732 & 71.7 & 73.0 \\
\hline Dabigatran & 9358 & 2.9 & 9237 & 98.7 & 7082 & 75.7 & 76.7 \\
\hline Rivaroxaban & 182 & 0.1 & 180 & 98.9 & 133 & 73.1 & 73.9 \\
\hline
\end{tabular}

$1.51 \pm 0.66$ and $3.08 \pm 1.23$, respectively. Over half $(54.6 \%)$ of the patients were male. The study sample was mostly from the North Central $(33.4 \%)$ and Southern $(32.9 \%)$ geographic areas of the USA. The most common $\mathrm{CHADS}_{2} / \mathrm{CHA}_{2} \mathrm{DS}_{2}$-VASc risk factor was age 75 years or older $(60.7 \%)$, followed by having a diagnosis of hypertension $(52.3 \%)$. There was substantial overlap among these risk factors, as evidenced by the fact that the percentages across $\mathrm{CHADS}_{2} / \mathrm{CHA}_{2} \mathrm{DS}_{2}$-VASc risk categories sum to well over $100 \%$.

Of the total number of NVAF patients identified, $299,716(92.5 \%)$ were prescribed chronic medications other than oral anticoagulants, and 215,527 (66.5\%; $95 \%$ confidence interval [CI] 66.4-66.6) were identified as taking these medications more than once per day (Table 2). Among patients who were prescribed chronic medications, $71.9 \%$ (95\% CI: 71.8-72.0) were identified as taking their medications more than once per day.

The percentages of NVAF patients prescribed chronic medications other than oral anticoagulants more than once per day by anticoagulation therapy group are also presented in Table 2. Nearly half of all patients (46.8\%) were not on prescription oral anticoagulation therapy in the last 90 days of the follow-up period. Of the remaining population $(53.2 \%)$, warfarin was the most common therapy (50.2\% of the sample), followed by dabigatran $(2.9 \%)$ and rivaroxaban $(0.1 \%)$.

The percentage of patients who were taking chronic medications more than once per day was smaller in the no anticoagulant group than among patients on an anticoagulant (60.3 vs. $71.9 \%$, respectively). Among those patients receiving anticoagulants, the percentage was highest for patients on dabigatran $(75.7 \%)$ with small differences across the individual anticoagulant groups. Results appear similar when defining the anticoagulation treatment groups according to the medication they were taking on the last day of the follow-up period.

Among the 299,716 NVAF patients who took chronic medications, the mean number of medications taken was 6.9 and the median was 6 . The mean number of therapeutic
Table 3 Top 25 most commonly prescribed therapeutic classes of medications in the 12 months following the first diagnosis of nonvalvular atrial fibrillation (NVAF)

\begin{tabular}{lll}
\hline Therapeutic class & $N$ & $\%$ \\
\hline Beta blockers ${ }^{\mathrm{a}}$ & 194,461 & 60.0 \\
Antihyperlipidemic drugs, NEC & 173,680 & 53.6 \\
Calcium channel blockers & 108,558 & 33.5 \\
ACE inhibitors & 104,082 & 32.1 \\
Loop diuretics & 100,383 & 31.0 \\
Gastrointestinal drugs, NEC & 76,905 & 23.7 \\
Cardiac drugs, NEC & 70,193 & 21.7 \\
Cardiac glycosides & 66,534 & 20.5 \\
Thyroid/hormones & 63,348 & 19.5 \\
Potassium supplements & 62,999 & 19.4 \\
Antidepressants & 60,060 & 18.5 \\
Miscellaneous therapeutic agents, NEC & 56,629 & 17.5 \\
Antiarrhythmic agents & 56,103 & 17.3 \\
Antidiabetic agents, miscellaneous & 47,539 & 14.7 \\
Antiplatelet agents, NEC & 33,027 & 10.2 \\
Thiazides and related diuretics & 32,452 & 10.0 \\
Sulfonylurea antidiabetic agents & 31,281 & 9.6 \\
Potassium-sparing diuretics & 30,582 & 9.4 \\
Adrenals and combinations, NEC & 30,530 & 9.4 \\
Benzodiazepines & 26,853 & 8.3 \\
Hypotensive agents, NEC & 25,540 & 7.9 \\
Opiate agonists & 22,947 & 7.1 \\
Vasodilating agents, NEC & 22,626 & 7.0 \\
Insulin agents & 22,139 & 6.8 \\
Antigout agents, NEC & 22,125 & 6.8 \\
\hline & &
\end{tabular}

$N E C$ not elsewhere classified

${ }^{\text {a }}$ Cardiac class of medications only

b Medications in this class included, but were not limited to, finasteride, tamsulosin, dutasteride, alfuzosin, and the bisphosphonate class of medications

classes was 6.4 and the median was 6 . The most commonly prescribed therapeutic classes of medications are listed in Table 3. Beta blockers and antihyperlipidemic drugs were 


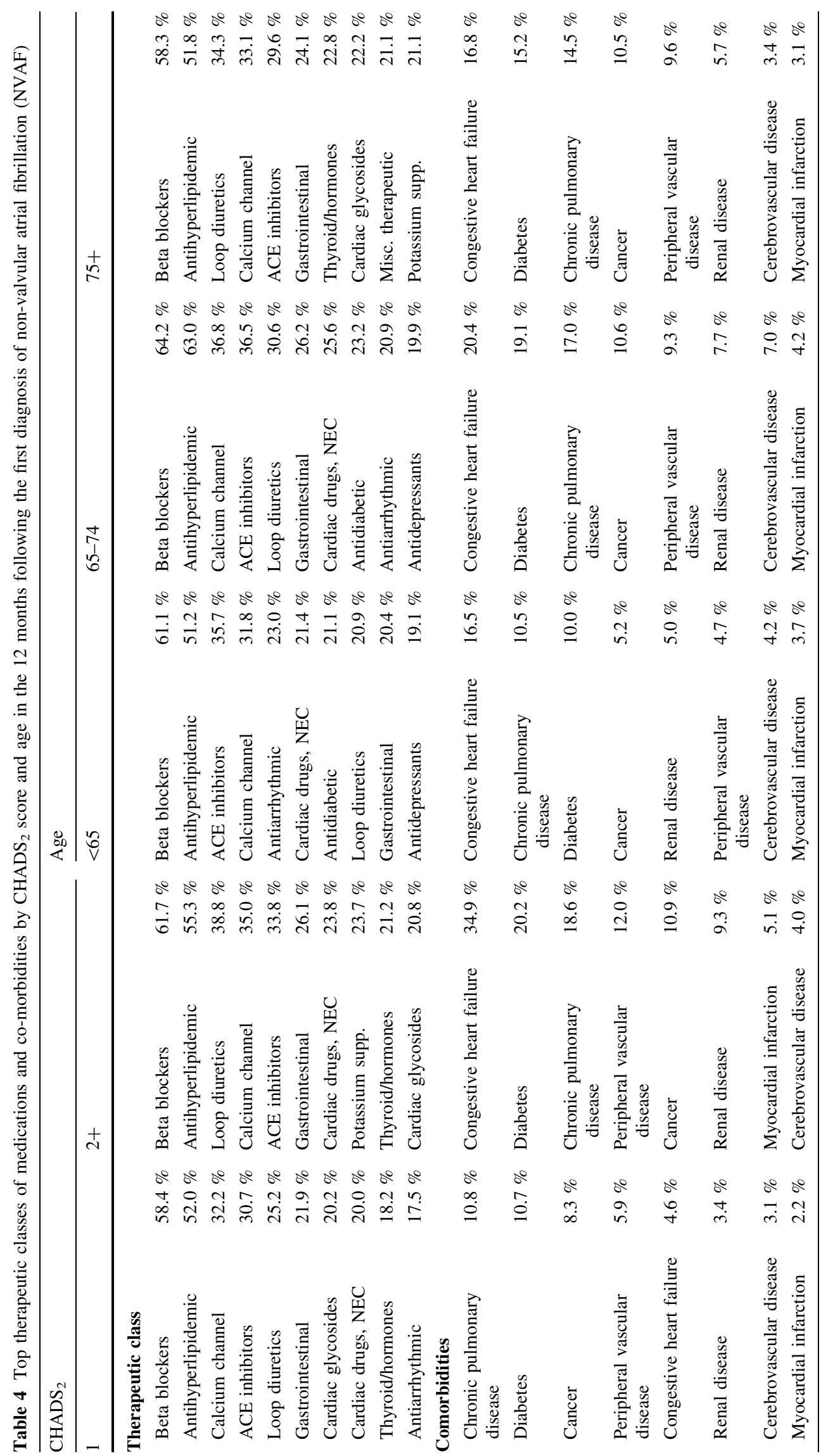


the most common therapeutic classes and were taken by 60.0 and $53.6 \%$ of those in our study sample, respectively.

Table 4 illustrates the most common therapeutic classes of medications and co-morbidities by $\mathrm{CHADS}_{2}$ score and age. Beta blockers were the most common class of medication across both $\mathrm{CHADS}_{2}$ score categories and all age groups $\left(58.4 \%\right.$ for $\mathrm{CHADS}_{2}=1$ and $61.7 \%$ for $\mathrm{CHADS}_{2}$ $\geq 2$; and $61.1,64.2$, and $58.3 \%$ for ages $<65,65-74$, and $75+$, respectively). The next most commonly prescribed chronic medications were antihyperlipidemics, calcium channel blockers, ACE Inhibitors, and loop diuretics, which generally increased with $\mathrm{CHADS}_{2}$ score and peaked in the 65- to 74-year age group.

Congestive heart failure was the most common comorbidity for the $\mathrm{CHADS}_{2} \geq 2$ score category $(34.9 \%)$ and all age groups $(16.5,20.4$, and $16.8 \%$ for ages $<65,65-74$, and $75+$ years, respectively), while chronic pulmonary disease was the most common co-morbidity for the $\mathrm{CHADS}_{2}=1$ score category $(10.8 \%)$. Diabetes and chronic pulmonary disease were the next most common comorbidities for the $\mathrm{CHADS}_{2} \geq 2$ score category and all age groups, while diabetes and cancer were the next most common co-morbidities for the $\mathrm{CHADS}_{2}=1$ score category. Table 4 highlights that NVAF patients are prescribed multiple medications from several therapeutic classes, have various co-morbidities, and, therefore, underscores the clinical complexity of the NVAF patient.

\section{Discussion}

This study examined the clinical and demographic characteristics of patients with NVAF who have at least one $\mathrm{CHADS}_{2}$ risk factor for stroke in a real world setting. We found that $92.5 \%$ of these patients take chronic medications other than oral anticoagulants, and of these patients, $71.9 \%$ take these chronic medications more than once per day. We also found that among our sample of NVAF patients with a $\mathrm{CHADS}_{2}$ score greater than one, the average $\mathrm{CHADS}_{2}$ and $\mathrm{CHA}_{2} \mathrm{DS}_{2}$-VASc scores were 1.51 and 3.08, respectively, with patients taking an average of 6.9 chronic medications from an average of 6.4 therapeutic classes. These results underscore the clinical complexity of NVAF patients.

Many factors go into choice of drug therapy. Once daily administration, versus medications that must be taken multiple times per day, may be an important factor affecting drug choice. The relationship between frequency of administration and adherence has been examined in previous studies. Results have been mixed, with some studies showing that once a day drugs are more convenient for patients, which may result in better adherence [13, 14], while a review by Claxton et al. found that there was no significant difference in compliance between once daily versus twice daily regimens [15].

Although previous studies have described characteristics of patients with NVAF and patterns of oral anticoagulant use in this patient population [17, 18], this retrospective database study examines the extent to which patients with NVAF take a variety of different chronic medications other than oral anticoagulants more than once a day. Compared to the earlier Phase III clinical trials with novel oral anticoagulants [19], our study sample had approximately the same age distribution [10-12], although the proportion of the sample that was male was higher in all the Phase III clinical studies compared to our study sample. The average $\mathrm{CHADS}_{2}$ score for our sample was slightly lower than that seen in the Phase III trials [1.51 vs. 2.1 for both the RE-LY (dabigatran) and ARISTOTLE (apixaban) Phase III studies, and 3.5 for the ROCKET-AF (rivaroxaban) Phase III study], although this is most likely due to differences in the study design and methods across these studies.

The patient demographic and stroke risk characteristics of our study sample are also comparable to earlier MarketScan studies, as well as the ORBIT-AF Registry from 174 community based outpatient practices enrolled from 2010-2011 [20]. Studies by Zimetbaum et al. [17], Casciano et al. [5], and Naccarelli et al. [18] that used MarketScan data from 2003-2007, 2003-2007, and 2004-2005, respectively, found similar distributions of age and gender for their NVAF samples. As for stroke risk factors contributing to the $\mathrm{CHADS}_{2}$ score, hypertension accounted for the largest percentage in all of the previously noted studies (Phase III clinical trial and MarketScan studies). CHF was the second most common stroke risk factor in all studies, except for the Casciano et al. [5] study, where diabetes was the second most common and CHF was the third most common.

In our study, there were 97,535,597 active patients in the MarketScan database (2013), with 1,499,871 (1.54\%) of those patients with at least one diagnosis of atrial fibrillation. When comparing our study sample to an earlier MarketScan study by Naccarelli [18], there were 21,648,681 active patients in their MarketScan database (2004-2005), with 313,382 (1.45\%) of those patients only having a diagnosis of atrial fibrillation. When comparing our study to the US Census population in 2010 of an estimated 308.7 million citizens [22], the annual prevalence of atrial fibrillation in 2010 was estimated at 5.2 million $(1.68 \%$ ) cases in the US general population [23]. Colilla states that the prevalence of atrial fibrillation is projected to be 12.1 million by 2030 and is the result of an aging population and that the incidence rate of atrial fibrillation is also increasing [23].

It is interesting that almost half $(46.8 \%)$ of our sample of NVAF patients with $\mathrm{CHADS}_{2} \geq 1$ received no oral 
anticoagulant treatment. This is comparable to the rate found by Zimetbaum et al. $(42.6 \%)$ in their study of MarketScan data from 2003 through 2007 [17]. Some of these patients may be taking aspirin over the counter, which would not be captured in our claims database. In addition, 64,826 of the 135,964 (47.7\%) patients in our sample with $\mathrm{CHADS}_{2} \geq 2$ and 135,956 of the 295,311 (46.0\%) patients with $\mathrm{CHA}_{2} \mathrm{DS}_{2}$-VASc $\geq 2$ received no oral anticoagulation treatment, which according to the recent 2014 AHA/ACC/HRS Guideline for the Management of Patients with Atrial Fibrillation, suggests suboptimal use of NVAF thromboprophylaxis [6, 21]. Among those receiving oral anticoagulant treatment, warfarin remains the dominant treatment modality (50.2\%), despite the need for maintaining a consistent diet with respect to vitamin $\mathrm{K}$ intake and frequent INR monitoring. Very few patients received dabigatran $(2.9 \%)$ or rivaroxaban $(0.1 \%)$, most likely due to their recent introduction to the market.

\subsection{Limitations}

Although this study has several strengths, such as the large sample size, the ability to track outpatient prescriptions and refills over time, and the nationwide sample, several limitations deserve comment. Primary among these is the fact that we cannot determine what instructions patients are given with respect to frequency of administration; we can only infer the frequency with which patients take chronic medications based on the FDA approved prescribing information and other characteristics of the medications and/or prescription records. For example, we categorize a patient that has been prescribed two dosage units a day as a patient that takes medication twice daily (barring any additional information) if the sum of the milligrams is equal to an available dose of the same medication. While this is the best categorization for the majority of patients that fall under this scenario, we recognize that patients may be incorrectly categorized if in fact they are instructed to take "up to" two dosage units a day to allow them flexibility in treating their condition (for example, someone who is instructed to take different doses based on blood pressure readings). In this last scenario, we recognize that the patient with flexible dosing instructions is "at risk" of needing to take their medication more than once per day and categorize them accordingly. We also acknowledge that some patients may be prescribed two smaller dosage units to be taken simultaneously, instead of a larger dosage unit strength, to allow for dosing titration, flexibility and ease of administration.

Another limitation is that our ability to identify comorbid conditions for computing the $\mathrm{CHADS}_{2}$ and $\mathrm{CHA}_{2} \mathrm{DS}_{2}$-VASc measures was limited by the 6 month baseline period used to identify these conditions. In addition, because we rely on claims data and not detailed clinical data, we may underestimate the percentage of patients with some components of the $\mathrm{CHADS}_{2}$ measure, such as history of $\mathrm{CHF}$, hypertension, diabetes, and prior stroke/TIA, which could result in a lower calculated $\mathrm{CHADS}_{2}$ score.

Also, another limitation is that the $\mathrm{CHA}_{2} \mathrm{DS}_{2}$-VASc calculations were based on the selection criteria in the study, a $\mathrm{CHADS}_{2}$ score of $\geq 1$, which would have underestimated capturing those patients with criteria specific to the $\mathrm{CHA}_{2} \mathrm{DS}_{2}$-VASc scoring system such as vascular disease, age 65-74 years and female gender. Finally, use of over-the-counter medications such as aspirin is likely to be under-reported in the claims data; therefore, use of aspirin was not assessed in this study.

\section{Conclusion}

Our study demonstrates that patients with NVAF are clinically complex, and often take chronic medications, other than oral anticoagulants, more than once a day and that this may diminish the potential convenience of a once daily oral anticoagulant medication regimen. Further, the clinical complexity of this patient population may require consideration of other factors when deciding between a once a day versus a more than once a day dosing of an oral anticoagulant. More research is needed to understand the impact of prescribing a once daily oral anticoagulant medication versus a more than once a day oral anticoagulant medication on adherence when patients are already taking chronic medications more than once per day.

Author contributions Each author (P. Kocis, G. Liu, D. Makenbaeva, J. Trocio, D. Velott, J. Trainer, Y. Abdulsattar, M. Molina, and D. Leslie) made substantial contributions to all aspects of this manuscript including conception and planning of the work that led to the manuscript or acquisition, analysis and interpretation of the data; drafting and/or critical revision of the manuscript for important intellectual content; and approval of the final submitted version of the manuscript for the entire content of this manuscript.

\section{Compliance with Ethical Standards}

Ethical approval This article does not contain any studies with human participants performed by any of the authors. This study was approved by the Institutional Review Board at the Penn State Health, Milton S. Hershey Medical Center, Hershey, PA, USA.

Conflict of interest Authors P. Kocis, G. Liu, D. Velott, and D. Leslie of Penn State University conducted this study under a research services agreement funded by Bristol-Myers Squibb and Pfizer. Authors D. Makenbaeva and M. Molina are Bristol-Myers Squibb employees with stock/stock options. Authors J. Trocio, J. Trainer and Y. Abdulsattar are Pfizer employees with stock/stock options. 
Funding This study was sponsored by Bristol-Myers Squibb and Pfizer.

Open Access This article is distributed under the terms of the Creative Commons Attribution-NonCommercial 4.0 International License (http://creativecommons.org/licenses/by-nc/4.0/), which permits any noncommercial use, distribution, and reproduction in any medium, provided you give appropriate credit to the original author(s) and the source, provide a link to the Creative Commons license, and indicate if changes were made.

\section{References}

1. Fuster V, Rydén LE, Cannom DS, Crijns HJ, Curtis AB, Ellenbogen KA, Halperin JL, Kay GN, Le Huezey JY, Lowe JE, Olsson SB, Prystowsky EN, Tamargo JL, Wann LS, Smith SC, Priori SG, Estes NA, Ezekowitz MD, Jackman WM, January CT, Page RL, Slotwiner DJ, Stevenson WG, Tracy CM, Jacobs AK, Anderson JL, Albert N, Buller CE, Creager MA, Ettinger SM, Guyton RA, Hochman JS, Kushner FG, Ohman EM, Tarkington LG, Yancy CW, Force ACoCFAHAT. 2011 accf/aha/hrs focused updates incorporated into the acc/aha/esc 2006 guidelines for the management of patients with atrial fibrillation: a report of the American college of cardiology foundation/american heart association task force on practice guidelines. Circulation. 2011;123:e269-367.

2. Wolf PA, Abbott RD, Kannel WB. Atrial fibrillation as an independent risk factor for stroke: the framingham study. Stroke. 1991;22:983-8.

3. Iwasaki K, Pyenson B. Milliman Client Report: Non-valvular atrial fibrillation \& anticoagulation therapy: an acturial study of the medicare population. August, 2010. Retrieved http://us.milliman. com/uploadedFiles/insight/research/health-rr/non-valvular-atrialfibrillation.pdf Accessed 13 Mar 2016.

4. Lip GY, Halperin JL. Improving stroke risk stratification in atrial fibrillation. Am J Med. 2010;123:484-8.

5. Casciano JP, Singer DE, Kwong WJ, Fox ES, Martin BC. Anticoagulation therapy for patients with non-valvular atrial fibrillation. Am J Cardiovasc Drugs. 2012;12:313-23.

6. January CT, Wann LS, Alpert JS, Calkins H, Cleveland JC, Cigarroa JE, Conti JB, Ellinor PT, Ezekowitz MD, Field ME, Murray KT, Sacco RL, Stevenson WG, Tchou PJ, Tracy CM, Yancy CW. 2014 aha/acc/hrs guideline for the management of patients with atrial fibrillation. A report of the american college of cardiology/american heart association task force on practice guidelines and the heart rhythm society. J Am Coll Cardiol. 2014;64(21):e1-e76.

7. Butt H, Allen E, Bollman J. A preparation from spoiled sweet clover [3, 3'-methylene-bis-(4-hydroxycoumarin)] which prolongs coagulation and prothrombin time of the blood: Preliminary report of experimental and clinical studies. Proc. Staff Meet. Mayo Clin. 1941;16:388-395.

8. Ansell J, Hirsh J, Poller L, Bussey H, Jacobson A, Hylek E. The pharmacology and management of the vitamin $\mathrm{k}$ antagonists: The seventh accp conference on antithrombotic and thrombolytic therapy. Chest. 2004;126:204S-33S.

9. Bauer KA. Pros and cons of new oral anticoagulants. Hematol Am Soc Hematol Educ Program. 2013;2013:464-70.
10. Granger CB, Alexander JH, McMurray JJ, Lopes RD, Hylek EM, Hanna M, Al-Khalidi HR, Ansell J, Atar D, Avezum A, Bahit MC, Diaz R, Easton JD, Ezekowitz JA, Flaker G, Garcia D, Geraldes M, Gersh BJ, Golitsyn S, Goto S, Hermosillo AG, Hohnloser SH, Horowitz J, Mohan P, Jansky P, Lewis BS, LopezSendon JL, Pais P, Parkhomenko A, Verheugt FW, Zhu J, Wallentin $\mathrm{L}$, Investigators ACa. Apixaban versus warfarin in patients with atrial fibrillation. N Engl J Med. 2011;365:981-92.

11. Connolly SJ, Ezekowitz MD, Yusuf S, Eikelboom J, Oldgren J, Parekh A, Pogue J, Reilly PA, Themeles E, Varrone J, Wang S, Alings M, Xavier D, Zhu J, Diaz R, Lewis BS, Darius H, Diener HC, Joyner CD, Wallentin L, Investigators R-LSCa. Dabigatran versus warfarin in patients with atrial fibrillation. N Engl J Med. 2009;361:1139-51.

12. Patel MR, Mahaffey KW, Garg J, Pan G, Singer DE, Hacke W, Breithardt G, Halperin JL, Hankey GJ, Piccini JP, Becker RC, Nessel CC, Paolini JF, Berkowitz SD, Fox KA, Califf RM, Investigators RA. Rivaroxaban versus warfarin in nonvalvular atrial fibrillation. N Engl J Med. 2011;365:883-91.

13. Ho PM, Bryson CL, Rumsfeld JS. Medication adherence: Its importance in cardiovascular outcomes. Circulation. 2009;119:3028-35.

14. Brown MT, Bussell JK. Medication adherence: Who cares? Mayo Clin Proc. 2011;86:304-14.

15. Claxton AJ, Cramer J, Pierce C. A systematic review of the associations between dose regimens and medication compliance. Clin Therap. 2001;23:1296-310.

16. Amin A, Stokes M, Wu N, Gatt E, Makenbaeva D, Wiederkehr D, Boulanger L. Application of randomized clinical trial data to actual practice: Apixaban therapy for reduction of stroke risk in non-valvular atrial fibrillation patients. Curr Med Res Opin. 2013;29:1253-61.

17. Zimetbaum PJ, Thosani A, Yu HT, Xiong Y, Lin J, Kothawala P, Emons M. Are atrial fibrillation patients receiving warfarin in accordance with stroke risk? Am J Med. 2010;123:446-53.

18. Naccarelli GV, Varker H, Lin J, Schulman KL. Increasing prevalence of atrial fibrillation and flutter in the united states. Am J Cardiol. 2009;104:1534-9.

19. Schneeweiss S, Gagne JJ, Patrick AR, Choudhry NK, Avorn J. Comparative efficacy and safety of new oral anticoagulants in patients with atrial fibrillation. Circ Cardiovasc Qual Outcomes. 2012;5:480-6.

20. Cullen MW, Kim S, Piccini JP, Ansell JE, Fonarow GC, Hylek EM, Singer DE, Mahaffey KW, Kowey PR, Thomas L, Go AS, Lopes RD, Chang P, Peterson ED, Gersh BJ, Investigators O-A. Risks and benefits of anticoagulation in atrial fibrillation: Insights from the outcomes registry for better informed treatment of atrial fibrillation (orbit-af) registry. Circ Cardiovasc Qual Outcomes. 2013;6:461-9.

21. Bungard TJ, Ghali WA, Teo KK, McAlister FA, Tsuyuki RT. Why do patients with atrial fibrillation not receive warfarin? Arch Intern Med. 2000;160:41-6.

22. United States Census Bureau. Population Distribution and Change: (March 2011). Population Distribution and Change: 2000 to 2010. Retrieved https://www.census.gov/prod/cen2010/ briefs/c2010br-01.pdf. Accessed 13 Mar 2016.

23. Colilla S, Crow A, Petkun W, Singer DE, Simon T, Liu X. Estimates of current and future incidence and prevalence of atrial fibrillation in the U.S. adult population. Am J Cardiol. 2013;112:1142-7. 